\title{
Effects of Cognitive Function and Naming Ability on the Quality of Communication Life in the Korean Elderly
}

\author{
Ji Young Park', Seong Hee Choi ${ }^{1,2}$, Kyoung jae Lee ${ }^{1,2}$, Chul-Hee Choi ${ }^{1,2}$ \\ 'Department of Audiology and Speech-Language Pathology, The Graduate School of Medical and Health Industry, Daegu Catholic University, Gyeong- \\ san, Korea \\ ${ }^{2}$ Department of Audiology and Speech-Language Pathology, College of Bio and Medical Sciences, Research Institute of Biomimetic Sensory Control, and \\ Catholic Hearing Voice Speech Center, Daegu Catholic University, Gyeongsan, Korea
}

\author{
Received: May 3, 2020 \\ Revised: July 2, 2020 \\ Accepted: July 7, 2020 \\ Correspondence: \\ Seong Hee Choi, PhD \\ Department of Audiology and \\ Speech-Language Pathology, \\ College of Bio and Medical Sciences, \\ Research Institute \\ of Biomimetic Sensory Control, and \\ Catholic Hearing Voice Speech Center, \\ Daegu Catholic University, \\ 13-13 Hayang-ro, Hayang-eup, \\ Gyeongsan 38430, Korea \\ Tel: +82-53-850-2542 \\ Fax: +82-53-359-6780 \\ E-mail: shgrace@cu.ac.kr
}

\begin{abstract}
Purpose: As old people age, their cognitive skills as well as naming ability decrease. In particular, dementia, along with memory, is a decline in other intellectual abilities that can interfere with everyday life. Therefore, the aim of this study was to explore the naming ability, cognitive function, and quality of communication life in the Korean elderly and thier relationship. Methods: A total of 50 Korean elderly people (25 normal, 25 elderly patients with mild cognitive impairment $(\mathrm{MCl})$ from Korean version of Montreal Cognitive Assessment (K-MoCA) ranged in age from 65 to 85 years old participated. The naming ability and quality of communication life were measured using short form of the Korean-Boston naming test (S-K-BNT) and the quality of communication life scale (QCL). Results: Significantly lower naming ability and poor QCL scores were observed in the elderly group with $\mathrm{MCl}$. In addition, significantly strong correlation was revealed between K-MoCA score and QCL $(r=0.728)$. All cognitive function including executive function, visuospatial ability, memory, attention, language, and orientation demonstrated significant relationship with QCL. Among the cognitive function, in particular, visuospatial ability showed the highest correlation with QCL $(r=0.626)$. Moreover, significantly moderate positive correlation $(r=0.620)$ was revealed between naming score and QCL. Conclusion: In current study, cognitive function as well as naming ability can be important diagnostic indice for predicting and determining good quality of communication life in elderly people.
\end{abstract}

Key Words: Cognitive function, Naming ability, Quality of communication life, The elderly.

\section{INTRODUCTION}

노인의 인구가 급속하게 증가하면서 우리나라는 노인 인구가 2000년 전체 인구의 $7 \%$ 를 넘어서며 고령화 사회에 진입하게 되었으며, 2017년 8월 말의 기준으로 '고령화 사회'에서 UN이 정한 '고령사회’로 진입하였다. 노인 인구가 증가함에 따라 노년 층에서는 노화로 인한 신체적, 생리적, 인지적 기능의 저하와 만성 질환과 정신·사회적 변화 등의 크고 작은 건강 문제에 직 면하게 되고, 이는 연령이 높아지게 될수록 질환을 지닌 노인의 비율이 증가함을 말한다(Kang et al., 2000; Lee, 2013a). 노인 의 흔한 질환에는 고혈압과 당뇨병, 만성 폐질환, 암, 뇌졸중, 심 장질환과 더불어 노화에 의한 정신기능의 장애 역시 다양하게 나타나며, 노인에게 있어서 인지기능의 변화는 노화에 따른 정

(c) This is an Open Access article distributed under the terms of the Creative Commons Attribution Non-Commercial License (https://creativecommons.org/licenses/by-nc/4.0) which permits unrestricted non-commercial use, distribution, and reproduction in any medium, provided the original work is properly cited.
신기능장애의 대표적 증상이다(Sung, 2007).

인지기능의 장애는 인간에게 있어 삶의 질 저하에 영향을 미 치게 되는 중요한 지표(Calero et al., 2013)이며, 사람이 사람답 게 살아가는 데 필요한 기능을 유지하는가를 판단하는 기준이 된다(Gorske et al., 2006). 하지만 평균수명의 연장으로 노인 인 구는 꾸준히 증가하였으며 살아가는 기간이 길어지게 됨에 따 라, 질병과 다양한 신체 정신장애로 인하여 인지장애를 경험하 게 될 가능성은 더욱 높아지고 있는 실정이며(Glisky, 2007), 삶 의 통합을 이루어야 할 시기인 노년기에 발생하는 인지장애에 관한 관심이 집중되고 있는 추세이다(Calero et al., 2013). 노인 들의 질환 중 퇴행성 뇌질환의 하나인 치매는 대표적인 인지장 애이며(Lee, 2013b), 우리나라 역시 인구 고령화와 더불어 치매 와 인지기능의 장애 또한 유병률이 증가하고 있다(Han, 2014).

인지장애를 가진 노년층은 기억력의 손상이 가장 큰 문제이 며, 이름대기 능력의 손상은 신경학적 질환을 지닌 환자뿐만 아 니라, 정상적인 노화 과정에 있는 노인에게서도 빈번하게 나타난 
다. Woo(2014)의 연구에서는 정상 노인 30명과 경도인지장애 노 인 33명의 이름대기 능력 및 주의력을 비교하였으며, 경도인지 장애 노인이 현저하게 이름대기 능력이 저하됨을 보고하였다. Kim et al.(2013)은 정상 노화 과정에 있는 65세 이상의 여성 노 인 46명을 대상으로 65 74세의 젊은 노인 집단과 75세 이상의 고령 노인 집단으로 구분하여 주의력 및 이름대기 능력의 차이 를 비교하였다. 연구 결과 주의력 과제에서 젊은 노인 집단이 고 령 노인 집단에 비해 점수가 유의하게 높았으며, 명사 동사 대면 이름대기검사에서는 고령 노인 집단이 젊은 노인 집단에 비해 유의하게 낮은 수행력을 보였다. Park \& Chey(2000)는 서울-경 기 지역에 거주하는 만 55 84세의 건강한 장노년 인구를 대상 으로 한국판 보스톤 이름대기검사의 단축형에 대한 노인 규준 을 보고하였다. $\operatorname{Kim} \& \operatorname{Kim}(2013)$ 은 60개 문항의 한국판 보스 턴 이름대기검사(Korean version of the Boston naming test, $\mathrm{K}-\mathrm{BNT}$ )를 일반 노년층의 이름대기 능력을 가장 잘 평가할 수 있는 15 개 문항의 검사(K-BNT-15)를 개발하여 K-BNT-15가 노화에 따른 대면이름대기 능력이 감소함을 보고하였다. 이처럼 노년층의 이름대기 능력은 노인의 의사소통에 매우 중요하다는 것을 시사한다.

한편, 노년기에 오는 인지장애의 경우 인지장애 정도가 경미 한 단계에서는 노인의 자존감을 훼손하며, 삶의 질을 감소시킨 다(Calero et al., 2013). 치매의 전 단계라 할 수 있는 경도인지장 애(mild cognitive impairment, $\mathrm{MCI}$ )는 치매는 아니지만 정상 적인 노화와 치매의 중간 단계로 감정의 변화 및 전반적인 일상 생활에 있어 수행하는 능력에 눈에 띄는 변화 없이 기능적 활 동과 사회생활이 가능한 상태이며, 비교적 정상적인 판단력을 가지고 있으나, 교육 수준이 같은 연령과 비교하였을 때 낮은 인지 수행을 보인다(Petersen et al., 2014). Petersen \& Morris(2003)는 65세 이상 정상인에서는 치매 발생이 1 2\%인 반면 $\mathrm{MCI}$ 에서는 10 15\%의 치매가 발병하고, 6년 장기 추적한 결과 $80 \%$ 가 치매로 진행한다고 하였으며, 이러한 인지장애는 노인 의 삶의 질뿐만 아니라 의사소통 삶의 질에도 영향을 미칠 수 있다. $\operatorname{Kim} \& \operatorname{Kim}(2009)$ 은 의사소통의 기능이 높을수록 노인 들의 전반적인 삶의 질이 높다고 보고하였으며, Lee(2019)는 정 상 노년층 22 명을 대상으로 노인의 의사소통 관련 삶의 질에 미치는 영향을 살펴보기 위하여 삶의 질, 인지, 심리, 정서적 요 인을 중심으로 살펴본 결과, 교육 수준과 전반적 인지 능력과 처리 속도 능력과 같은 조직화 능력이 주요한 예측 변인이라고 하였다. 의사소통 삶의 질을 평가하기 위한 주관적인 자가보고 식 검사는 의사소통 대상자와의 상호작용, 사회, 여가, 직장 및 교육 활동 참여에 미치는 영향을 평가하기 위하여 설계된 것으 로(Paul et al., 2004), Choi et al.(2011)이 한국어로 번안하여 청각장애 청소년을 대상으로 정상 청력 청소년과 비교하여 신
뢰도 및 타당도를 검증하였다.

지금까지의 선행연구를 살펴보았을 때 노년기에 나타날 수 있는 인지기능 저하와 노년기의 의사소통 문제 중 이름대기 능 력은 의사소통과 관련된 삶의 질에 영향을 미칠 수 있을 것으 로 추측되며, 특히 인지기능에 문제가 있는 노년층은 정상 노인 층에 비해 이러한 이름대기 능력이 저하되어 있다고 보고되고 있으나, 이러한 이름대기뿐만 아니라 인지기능에 속하는 지남 력, 시공간 능력, 주의력, 단기 기억 등이 의사소통과 관련된 삶 의 질에 어떠한 영향을 미치는지에 대한 연구는 아직까지 매우 미흡한 편이다.

따라서 본 연구에서는 65 85세의 정상 노년층과 $\mathrm{MCI}$ 노년 층의 의사소통 관련 삶의 질을 비교하고, 이름대기 능력과 인 지기능 관련 변인들이 의사소통의 삶의 질과 어떠한 상관성을 보이는지 살펴봄으로써 의사소통 관련 삶의 질을 예측할 수 있 는 유용한 변인들을 살펴보고자 한다.

\section{MATERIALS AND METHODS}

\section{연구 대상}

본 연구의 대상자는 대구경북 소재 노인 복지센터를 이용하 고 있는 65 세 이상 노년층 50 명을 대상으로 하였으며, 연령 범위 는 65 83세(평균연령 $75.04 \pm$ 4.46세)로 남성 14명, 여성 36명이 었다. 정상 노년층 집단과 $\mathrm{MCI}$ 집단을 분류하기 위하여 한국판 몬트리올 인지 평가(Korean version of Montreal Cognitive Assessment, K-MoCA) (Kang et al., 2009)를 사용하여 나이와 교육 수준에 따라 정해진 절단점 점수의 규준에 의거하여 절단 점 이상의 점수를 받은 대상은 정상 노년층 집단, 절단점 미만의 점수를 받은 대상은 $\mathrm{MCI}$ 노년층 집단으로 선별하여 구분하였다.

연구 참여자의 연령, 교육 연수, 성별 등 특성은 Table 1 에 제 시하였다.

\section{연구 도구}

한국판 몬트리올 인지 평가(Korean version of Montreal

Cognitive Assessment, K-MoCA)

연구 참여자들을 정상 노년층 집단과 $\mathrm{MCI}$ 노년층 집단으로

Table 1. Demographic characteristics of participants

\begin{tabular}{cccc}
\hline Group & Age $(\mathrm{yr})$ & $\begin{array}{c}\text { Education level } \\
(\mathrm{yr})\end{array}$ & $\begin{array}{c}\text { Sex } \\
(\mathrm{M}: \mathrm{F})\end{array}$ \\
\hline $\begin{array}{c}\text { Normal control } \\
(\mathrm{n}=25)\end{array}$ & $74.76( \pm 4.05)$ & $6.76( \pm 4.08)$ & $7: 18$ \\
$\mathrm{MCI}(\mathrm{n}=25)$ & $75.32( \pm 4.90)$ & $6.16( \pm 3.62)$ & $7: 18$ \\
\hline
\end{tabular}

MCI: mild cognitive impairment 
선별하고 인지기능의 하부 능력을 평가하기 위하여 $\mathrm{K}-\mathrm{MoCA}$ 를 사용하였다. $\mathrm{K}-\mathrm{MoCA}$ 는 집행기능(4점: 기호잇기검사, 공통 성 문제, 음소유창성), 시공간 구성 능력(4점: 육면체 그리기, 시 계 그리기), 기억력(5점: 5 단어 지연회상), 주의집중 능력(6점: 숫자 외우기, 박수 치기, 100에서 7씩 빼기), 언어기능(5점: 대면 이름대기, 따라 말하기), 지남력(6점: 일, 월, 년, 요일, 장소, 도 시이름) 등 6 개의 하위 영역으로 구성되어 있으며, 채점 방법은 각 항목의 문항에 따라 최소 0점에서 최대 6점까지이다.

단축형 한국판 보스턴 이름대기검사(Short form of the Korean-Boston naming test, S-K-BNT)

정상 노년층 집단과 $\mathrm{MCI}$ 집단의 이름대기 능력을 비교하기 위하여 단축형 한국판 보스턴 이름대기검사(Short form of the Korean-Boston naming test, S-K-BNT)를 시행하였다. S-K$\mathrm{BNT}$ 는 보스턴 이름대기검사(Boston naming test, BNT) (Kaplan et al., 1983)를 한국인들을 대상으로 재표준화한 한국 판 보스턴 이름대기검사(K-BNT) (Kim \& Na, 1997)의 단축형 형태의 검사로서 S-K-BNT는 짧은 시간 내에 치매 환자와 정 상 노인들을 효율적으로 변별할 수 있도록 개발되었다(Kang et al., 1999).

검사는 제시된 그림을 보고 사물의 이름을 말함으로써 대면 이름대기 능력(confrontation naming ability)을 평가하기 위한 과제로서 총 15 개의 문항으로 각 문항당 정반응하였을 때 1 점 을 부여하며 총점은 15 점이다.

의사소통 삶의 질 척도(Quality of communication life scale, $\mathrm{QCL})$

정상 노년층과 $\mathrm{MCI}$ 노년층의 의사소통 삶의 질을 측정하기 위하여 미국 말-언어-청각협회(American Speech-LanguageHearing Association, ASHA)의 의사소통 삶의 질 척도(ASHA quality of communication life scale, ASHA QCL) (Paul et al., 2004)를 사용하였으며, 국내에서 Choi et al.(2011)이 한국 의 문화적인 특성을 감안하고 고려하여 번안한 의사소통 삶의 질 한국어판을 사용하였다. 한국어판 의사소통 삶의 질 척도 는 총 18 개의 문항 중 노년층과 관련성이 적은 학교생활 관련 문항인 5 번을 제외하고 총 17 문항을 사용하였다. 각 문항은 $1 \sim 5$ 점까지의 척도로 이루어져 있으며, 총점은 85점이다.

\section{연구 절차}

모든 실험은 조용한 방에서 개별적으로 검사자와 피험자가 마주보고 앉은 일대일 상황에서 진행되었다. 검사 실시 전 피험 자는 기본 정보 및 사례력을 작성하였으며, 검사의 순서는 $\mathrm{K}-$ $\mathrm{MoCA}$ 검사 후 S-K-BNT, QCL 순서로 실시하였다.
정상 노년층과 $\mathrm{MCI}$ 노년층을 선별하기 위하여 $\mathrm{K}-\mathrm{MoCA}$ (Kang et al., 2009)를 사용하였으며, 본 검사 전 충분한 설명을 한 뒤 검사를 진행하였다. 각 하부 영역인 기호잇기검사(1점), 육면체 그리기(1점), 시계 그리기(3점)는 피험자가 검사자의 지 시를 듣고 직접 과제를 시행하도록 하였다. 지연회상의 경우 기 억력 즉각 회상 실시 후(점수 없음) 5 분 후 지연회상을 실시하 였으며, 점수 부여의 기준은 검사 방법과 검사지에 기술되어 있 는 부여 기준으로 하여 평가하였다.

단축형 한국판 보스턴 이름대기검사(Kang et al., 1999)를 사 용하여 이름대기검사를 실시하였으며, 검사 실시 전 피검자에 게 검사 방법에 대한 설명과 지시 사항을 전달 후 검사를 실시 하였다. 그림을 제시하고 15 초 이내에 정반응을 하였을 경우 1 점을 부여하였으며, 15 초 이상의 시간이 경과한 후에도 무반응 이거나 오반응 문항은 점수를 부여하지 않았다. 의미적 힌트나, 음절 힌트 제공은 하지 않았다.

본 연구에 참여한 대상자는 모두 비문맹으로 글자 읽기가 가 능하였으나, 노화로 인한 시력의 감퇴로 읽기에 어려움을 나타 내는 피검자의 경우 검사자가 문항을 읽어 주고 답을 하도록 하였다.

\section{통계 분석}

Statistics Package for Social Science (SPSS version 19.0, IBM Corp., Armonk, NY, USA)를 이용하여 S-K-BNT와 $\mathrm{QCL}$ 를 실시하여 원점수에 대하여 집단 간(정상 노년층, $\mathrm{MCI}$ 노년층) 평균과 표준편차를 구하였으며, 두 집단 간 정반응 총 점의 평균값을 비교하기 위하여 독립표본 $t$-검정을 실시하였다. $\mathrm{K}-\mathrm{MoCA}$ 와 QCL, S-K-BNT와 QCL의 상관성을 알아보기 위 하여 총점 값을 Pearson의 상관관계 분석을 실시하였다. 유의 수준은 $95 \%$ 로 하였다.

\section{RESULTS}

정상 노년층과 $\mathrm{MCl}$ 노년층의 이름대기와 의사소통 삶의 질 비교 정상 노년층과 $\mathrm{MCI}$ 노년층의 $\mathrm{S}-\mathrm{K}-\mathrm{BNT}$ 총점과 의사소통

Table 2. Descriptive statistics of S-K-BNT scores, the QCL scores between individuals with $\mathrm{MCl}$ and normal elderly

\begin{tabular}{rlrccc}
\hline \multicolumn{1}{c}{ Test } & \multicolumn{1}{c}{ Group } & Mean & SD & $t$ & $p$ \\
\hline S-K-BNT & Normal $(\mathrm{n}=25)$ & 9.52 & 3.16 & 5.235 & $<0.001$ \\
& MCI $(\mathrm{n}=25)$ & 5.44 & 2.27 & & \\
QCL & Normal $(\mathrm{n}=25)$ & 70.44 & 7.54 & 10.646 & $<0.001$ \\
& MCI $(\mathrm{n}=25)$ & 51.84 & 4.40 & & \\
\hline
\end{tabular}

S-K-BNT: short form of the Korean-Boston naming test, QCL: quality of communication life scale, MCI: mild cognitive impairment, SD: standard deviation 
삶의 질 척도 총점의 평균과 표준편차는 Table 2 와 같다.

이름대기검사에서 정상 노년층 집단의 $\mathrm{S}-\mathrm{K}-\mathrm{BNT}$ 원점수는 9.52( \pm 3.16$)$ 점, $\mathrm{MCI}$ 노년층 집단의 $\mathrm{S}-\mathrm{K}-\mathrm{BNT}$ 원점수는 $5.44( \pm 2.27)$ 점으로 정상 노년층 집단이 $\mathrm{MCI}$ 노년층 집단에 비해 통계적으로 유의하게 높았다 $[t(48)=5.235, p<0.001]$

(Table 2, Figure 1).

한편, 의사소통 삶의 질 척도 검사에서 정상 노년층 집단의 $\mathrm{QCL}$ 총점은 70.44( \pm 7.54)점, $\mathrm{MCI}$ 노년층 집단의 QCL 총점 은 51.84( \pm 4.40)점 이었으며(Figure 2), 독립표본 $t$-검정 결과 정상 노년층 집단이 $\mathrm{MCI}$ 노년층 집단에 비해 통계적으로 유의 하게 높았다 $(t=10.646, p<0.001)$.

정상 노년층 집단과 $\mathrm{MCI}$ 노년층 집단 간의 $\mathrm{QCL}$ 의 문항별

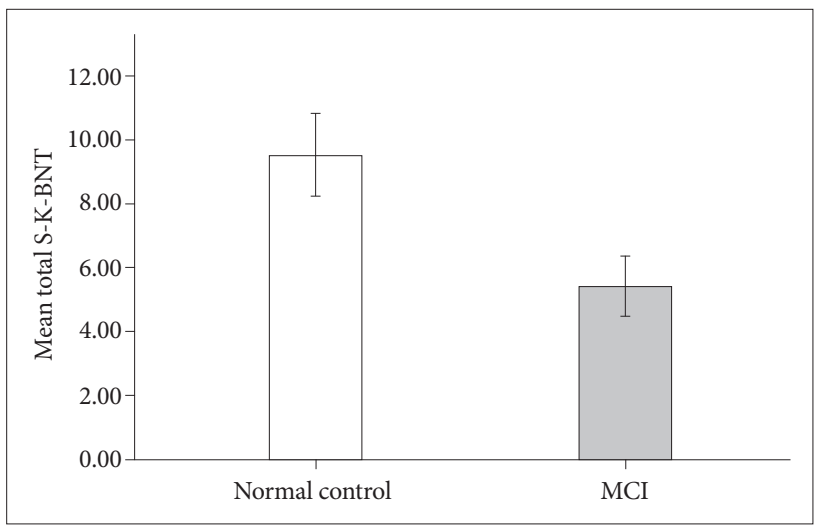

Figure 1. Comparison the naming ability by group. S-K-BNT: short form of the Korean-Boston naming test, $\mathrm{MCl}$ : mild cognitive impairment.
기술 통계량은 Table 3과 같으며, 정상 노년층 집단과 $\mathrm{MCI}$ 노 년층 집단의 $\mathrm{QCL}$ 의 1 17번 문항별 독립표본 $t$-검정 결과, 정 상 노년층 집단과 $\mathrm{MCI}$ 노년층 집단 간 모든 문항에서 통계적 으로 유의한 차이가 있었으며, 정상 노년층 집단이 $\mathrm{MCI}$ 노년층 집단에 비해 통계적으로 유의하게 높았다(Table 3).

\section{정상 노년층과 경도 인지장애군의 인지 영역별 수행력 비교}

정상 노년층과 경도 인지장애군의 $\mathrm{K}-\mathrm{MoCA}$ 총점과 인지 영 역별 점수의 평균과 표준편차는 Table 4와 같다.

$\mathrm{K}-\mathrm{MoCA}$ 총점은 정상 노년층은 20.48( \pm 3.83)점, $\mathrm{MCI}$ 노년 층은 $13.12( \pm 2.67)$ 점으로 $\mathrm{MCI}$ 집단이 유의하게 낮았다 $(p<$ 0.001). $\mathrm{K}-\mathrm{MoCA}$ 하위 능력 중 집행기능은 정상 노년층은

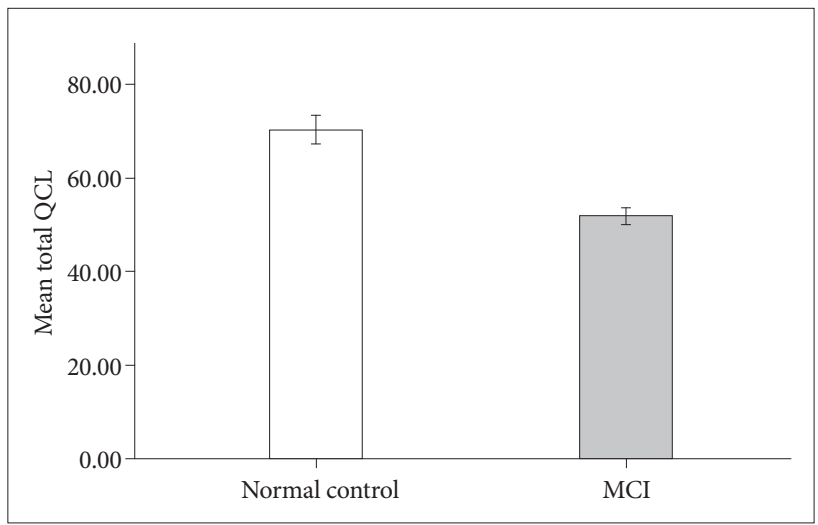

Figure 2. Comparison the quality of communication life by group. QCL: quality of communication life scale, $\mathrm{MCl}$ : mild cognitive impairment.

Table 3. Comparison of each item score by group in QCL

\begin{tabular}{|c|c|c|c|}
\hline Item & $\begin{array}{l}\text { Normal control } \\
\quad(\mathrm{n}=25)\end{array}$ & MCI $(n=25)$ & $t$ \\
\hline 1. I like talking to people. & $4.04( \pm 0.84)$ & $3.20( \pm 0.58)$ & $4.118^{* * *}$ \\
\hline 2. I'm not difficult to say. & $4.00( \pm 0.96)$ & $3.00( \pm 0.41)$ & $4.804^{* * *}$ \\
\hline 3. Compared to other people, my role at home is the same (ex. brother/sister, role as parent). & $4.04( \pm 0.98)$ & $3.20( \pm 0.50)$ & $3.823^{* *}$ \\
\hline 4. I am good myself. & $4.24( \pm 0.93)$ & $3.04( \pm 0.54)$ & $5.603^{* * *}$ \\
\hline 5. Stay in touch with my friends and relatives. & $4.12( \pm 0.83)$ & $2.88( \pm 0.53)$ & $6.295^{* * *}$ \\
\hline 6. When I talk, people put me in the conversation. & $4.04( \pm 0.98)$ & $3.20( \pm 0.50)$ & $3.823^{* *}$ \\
\hline 7. Understand the contents of TV dramas and news, and athletic competitions. & $4.08( \pm 0.81)$ & $2.80( \pm 0.50)$ & $6.709^{* * *}$ \\
\hline 8. I can use my cell phone. & $4.56( \pm 0.71)$ & $3.24( \pm 0.52)$ & $7.473^{* * *}$ \\
\hline 9. My daily life is fun. & $4.40( \pm 0.71)$ & $2.80( \pm 0.58)$ & $8.764^{* * *}$ \\
\hline 10. People understand what I say. & $4.28( \pm 0.74)$ & $3.08( \pm 0.40)$ & $7.154^{* * *}$ \\
\hline 11. I keep trying to understand when people don't understand what I'm saying. & $3.44( \pm 0.92)$ & $2.32( \pm 0.56)$ & $5.222^{* * *}$ \\
\hline 12. I make my own decisions. & $4.28( \pm 0.68)$ & $3.52( \pm 0.65)$ & $4.036^{* * *}$ \\
\hline 13. I am confident in communication. & $4.28( \pm 0.74)$ & $2.92( \pm 0.57)$ & $7.290^{* * *}$ \\
\hline 14. I do external activities (ex. sports, dining out, performance viewing, meetings, etc.). & $3.88( \pm 0.93)$ & $2.80( \pm 0.76)$ & $4.495^{* * *}$ \\
\hline 15. I help with household chores (ex. shopping, cooking, repairing, etc.). & $4.12( \pm 0.73)$ & $3.56( \pm 0.71)$ & $2.754^{* *}$ \\
\hline 16. Confidently say my opinion. & $4.24( \pm 0.72)$ & $3.36( \pm 0.49)$ & $5.036^{* * *}$ \\
\hline 17. Generally, my quality of life is good and happy. & $4.40( \pm 0.65)$ & $2.92( \pm 0.49)$ & $9.109^{* * *}$ \\
\hline
\end{tabular}

${ }^{* *} p<0.01,{ }^{* * *} p<0.001$. QCL: quality of communication life scale, MCI: mild cognitive impairment 
$1.64( \pm 1.25)$ 점, $\mathrm{MCI}$ 노년층은 $0.32( \pm 0.48)$ 점으로 $\mathrm{MCI}$ 집단 이 유의하게 낮았다 $(p<0.001)$. 시공간 구성 능력은 정상 노년 층은 3.00( \pm 0.65)점, $\mathrm{MCI}$ 노년층은 $1.68( \pm 0.90)$ 점으로 $\mathrm{MCI}$ 집단이 유의하게 낮았다 $(p<0.001)$. 기억력의 경우 정상 노년 층은 2.20( \pm 1.71$)$ 점, $\mathrm{MCI}$ 노년층은 $0.80( \pm$ 0.87)점으로 $\mathrm{MCI}$ 집단이 유의하게 낮았다 $(p<0.01)$. 주의집중력은 정상 노년층 은 3.96( \pm 1.40$)$ 점, $\mathrm{MCI}$ 노년층은 2.16( \pm 1.28$)$ 점으로 $\mathrm{MCI}$ 집 단이 유의하게 낮았으며 $(p<0.001)$, 언어 능력은 정상 노년층 은 3.92( \pm 0.91)점, $\mathrm{MCI}$ 노년층은 2.84( \pm 1.14$)$ 점으로 $\mathrm{MCI}$ 집 단이 유의하게 낮았다 $(p<0.01)$. 지남력의 경우 정상 노년층 은 5.76( \pm 0.44)점, $\mathrm{MCI}$ 노년층은 5.32( \pm 0.80$)$ 점으로 $\mathrm{MCI}$ 집 단이 유의하게 낮았다 $(p<0.05)$.

Table 4. Comparison of cognitive function using K-MoCA between normal and $\mathrm{MCl}$ group

\begin{tabular}{llrrc}
\hline \multicolumn{1}{c}{ K-MoCA } & \multicolumn{1}{c}{ Group } & Mean & SD & \multicolumn{1}{c}{$t$} \\
\hline Total & Normal $(\mathrm{n}=25)$ & 20.48 & 3.83 & $7.884^{* * *}$ \\
& MCI $(\mathrm{n}=25)$ & 13.12 & 2.67 & \\
Executive function & Normal $(\mathrm{n}=25)$ & 1.64 & 1.25 & $4.919^{* * *}$ \\
& MCI $(\mathrm{n}=25)$ & 0.32 & 0.48 & \\
Visuospatial ability & Normal $(\mathrm{n}=25)$ & 3.00 & 0.65 & $5.959^{* * *}$ \\
& MCI $(\mathrm{n}=25)$ & 1.68 & 0.90 & \\
Memory & Normal $(\mathrm{n}=25)$ & 2.20 & 1.71 & $3.656^{* *}$ \\
Attention & MCI $(\mathrm{n}=25)$ & 0.80 & 0.87 & \\
& Normal $(\mathrm{n}=25)$ & 3.96 & 1.40 & $4.746^{* * *}$ \\
Language & MCI $(\mathrm{n}=25)$ & 2.16 & 1.28 & \\
& Normal $(\mathrm{n}=25)$ & 3.92 & 0.91 & $3.697^{* *}$ \\
Orientation & MCI $(\mathrm{n}=25)$ & 2.84 & 1.14 & \\
& Normal $(\mathrm{n}=25)$ & 5.76 & 0.44 & $2.410^{*}$ \\
\hline
\end{tabular}

${ }^{*} p<0.05,{ }^{* *} p<0.01,{ }^{* * *} p<0.001$. K-MoCA: Korean version of Montreal Cognitive Assessment, MCI: mild cognitive impairment, SD: standard deviation

\section{의사소통 삶의 질 척도와 이름대기 및 인지 능력 상관}

의사소통 삶의 질 척도 $(\mathrm{QCL})$ 의 총점과 이름대기(S-K-BNT) 총점의 상관관계를 살펴본 결과, S-K-BNT와 QCL은 통계적으 로 유의하게 중간 정도의 양의 상관관계를 보였다 $(\mathrm{r}=0.620$, $p<0.01$ ) (Table 5, Figure 3). 의사소통 삶의 질 척도(QCL)의 총점과 $\mathrm{K}-\mathrm{MoCA}$ 총점 및 하위 인지 능력 간 상관관계는 Table 5 와 같다. QCL과 $\mathrm{K}-\mathrm{MoCA}$ 총점은 통계적으로 유의하게 높은 양(+)의 상관관계를 보였으며 $(\mathrm{r}=0.728, p<0.01)$ (Figure 4), $\mathrm{K}-\mathrm{MoCA}$ 하위 능력인 집행 능력(executive function)과 $\mathrm{QCL}$ 은 통계적으로 중간 정도의 양 $(+)$ 의 상관관계를 보였고 $(\mathrm{r}=$ 0.481, $p<0.01$ ), 시공간 구성 능력(visuospatial ability)의 점수 와 $\mathrm{QCL}$ 총점은 높은 양의 상관관계를 나타내었다 $(\mathrm{r}=0.626$, $p<0.01$ ) 한편 기억력(memory)의 점수와 $\mathrm{QCL}$ 총점은 중간 정도의 상관 $(\mathrm{r}=0.492, p<0.01)$ 을 나타내었으며, 주의집중력 (attention) 점수와 $\mathrm{QCL}$ 총점은 중간 정도의 상관 $(\mathrm{r}=0.589$, $p<0.01$ )을 보였고, 언어 능력(language ability)의 점수와 $\mathrm{QCL}$ 총점 $(\mathrm{r}=0.414, p<0.01)$ 은 중간 정도의 상관관계를 보였으며, 지남력(orientation)의 점수와 $\mathrm{QCL}$ 총점은 통계적으로 경도의 유의한 양(+)의 상관관계를 보였다 $(\mathrm{r}=0.345, p<0.05)$ (Table 5).

\section{DISCUSSIONS}

본 연구는 정상 노년층 집단과 $\mathrm{MCI}$ 노년층 집단의 의사소통 삶의 질의 특성을 비교하고, 의사소통 삶의 질에 미치는 변인 중 이름대기 능력과 인지 능력의 영향을 살펴보기 위하여 대면 이름대기검사인 S-K-BNT와 인지능력검사인 $\mathrm{K}-\mathrm{MoCA}$ 를 사 용하여 의사소통 삶의 질에 미치는 영향을 분석하였다.

\section{이름대기 능력과 의사소통 삶의 질}

본 연구에서 $\mathrm{MCI}$ 노년층 집단은 정상 노년층 집단에 비해 이 름대기 능력이 유의하게 낮았으며, 이러한 결과는 $\mathrm{MCI}$ 환자군

Table 5. Correlation among QCL, cognitive function, and naming ability

\begin{tabular}{|c|c|c|c|c|c|c|c|c|c|}
\hline & QCL & $\mathrm{CF}$ & $\mathrm{EF}$ & VSA & Memory & Attention & Language & Orientation & Naming \\
\hline QCL & 1 & & & & & & & & \\
\hline CF & $0.728^{* *}$ & 1 & & & & & & & \\
\hline $\mathrm{EF}$ & $0.481^{* *}$ & $0.726^{* *}$ & 1 & & & & & & \\
\hline VSA & $0.626^{* *}$ & $0.752^{* *}$ & $0.509^{* *}$ & 1 & & & & & \\
\hline Memory & $0.492^{* *}$ & $0.743^{* *}$ & $0.462^{* *}$ & $0.415^{* *}$ & 1 & & & & \\
\hline Attention & $0.589^{* *}$ & $0.789^{* *}$ & $0.397^{* *}$ & $0.521^{* *}$ & $0.465^{* *}$ & 1 & & & \\
\hline Language & $0.414^{* *}$ & $0.629^{* *}$ & $0.419^{* *}$ & $0.371^{* *}$ & 0.273 & $0.447^{* *}$ & 1 & & \\
\hline Orientation & $0.345^{*}$ & $0.326^{*}$ & 0.145 & $0.319^{*}$ & 0.209 & 0.120 & -0.059 & 1 & \\
\hline Naming & $0.620^{* *}$ & $0.749^{* *}$ & $0.609^{* *}$ & $0.513^{* *}$ & $0.556^{* *}$ & $0.562^{* *}$ & $0.551^{* *}$ & 0.142 & 1 \\
\hline
\end{tabular}
${ }^{*} p<0.05,{ }^{* *} p<0.01$. QCL: quality of communication life scale, CF: cognitive function (Korean version of Montreal Cognitive Assessment), EF: executive function, VSA: visuospatial ability 


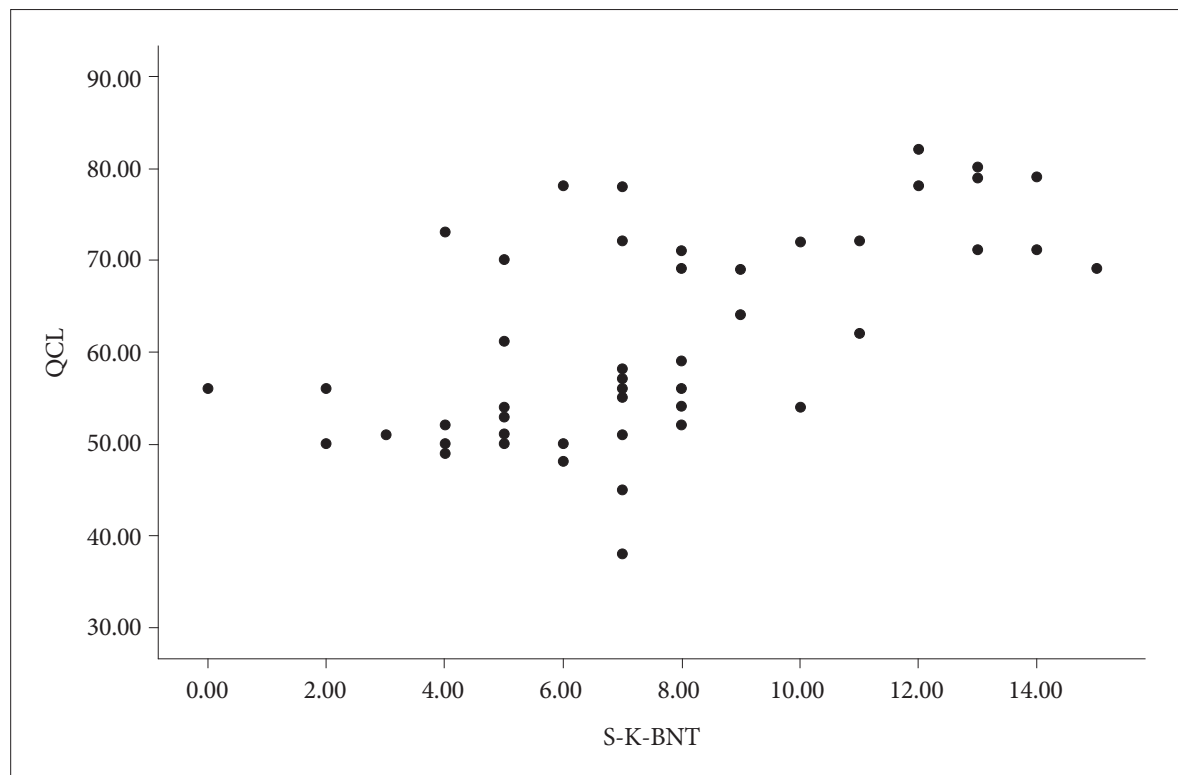

Figure 3. Relationship between $Q C L$ and naming. QCL: quality of communication life scale, S-K-BNT: short form of the Korean-Boston naming test.

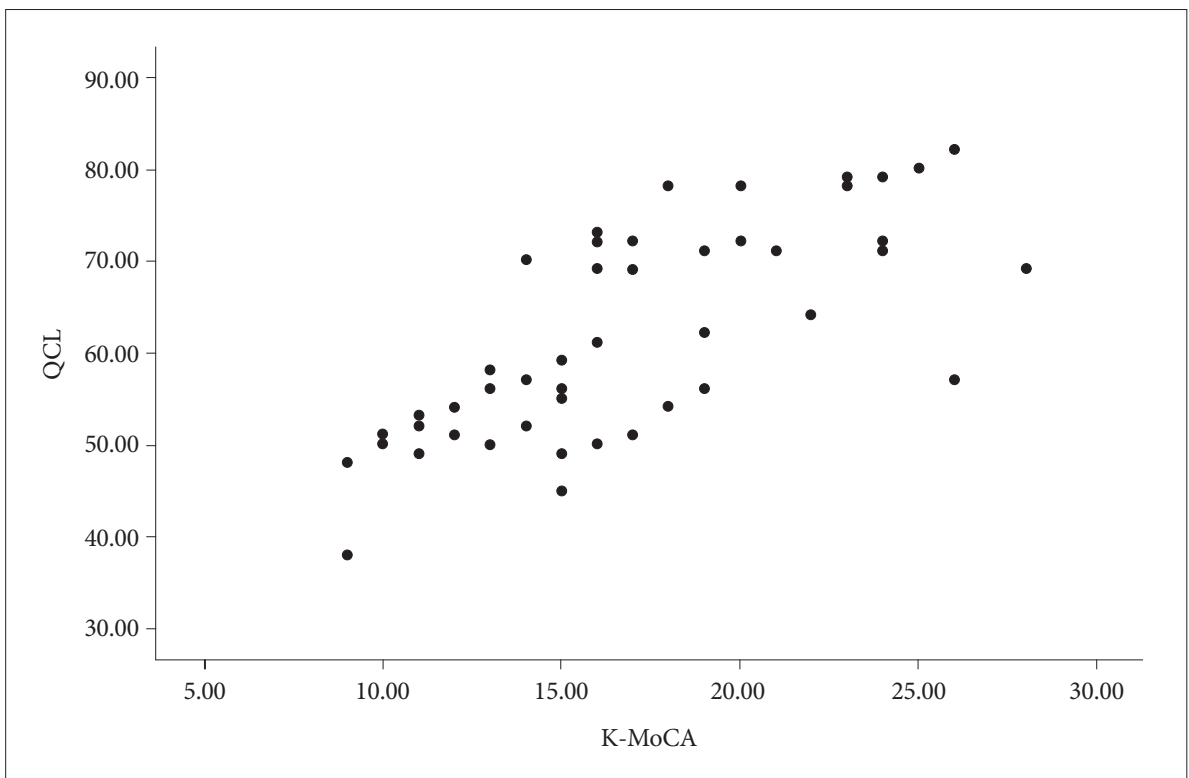

Figure 4. Relationship between QCL and cognitive function. QCL: quality of communication life scale, K-MoCA: Korean version of Montreal Cognitive Assessment.

과 정상군 두 집단 간 대면이름대기 능력을 비교한 선행연구들 의 결과와도 일치하는 결과이다(Balthazar et al., 2008; Duong et al., 2006; Jefferson et al., 2007; Johns et al., 2012; Mioshi et al., 2006; Woo \& Kim, 2015). 노인의 경우 언어기능 중 의 미적 접근성의 측면에서는 수행력이 보존되지만 사물이나 사 람 이름대기 과제에서는 큰 어려움을 보이며(Juncos-Rabadán et al., 2005; Verhaeghen, 2003), 이로 인하여 이름대기는 노인 들이 보편적으로 어려움을 겪는 영역에 해당한다(Maseda et al., 2014). 특히, 대면이름대기 과제인 보스턴 이름대기검사에서 의 수행력을 살펴보면 인지기능에 문제가 있는 노년층이 정상 노년층에 비해 저하되었다(Hwang \& Kim, 2014). 인지기능의 장
애인 $\mathrm{MCI}$ 역시 의미지식이 저하되면서 낱말 찾기(word-finding)에 있어 어려움을 보이게 되고, 이름대기의 어려움으로 나 타난다(Caccappolo-Van Vliet et al., 2003; Swainson et al., 2001). 선행연구에 의하면 대면이름대기에 있는 중요한 인지 영 역인 의미기억의 경우 $\mathrm{MCI}$ 에서 그 저하가 가장 두드러지게 나 타나며, 이로 인하여 어휘 및 의미 영역이 저하되며 이름대기 및 어휘유창성 등의 과제에서 낮은 수행력을 보이게 된다고 하 였다. 일반적으로 언어 능력의 저하 중 의미적 측면은 좌반구의 내측측두엽(medial temporal lobe)의 손상과 관련이 있다고 알 려져 있으며(Morra et al., 2009), 또 다른 요인으로는 노년층의 인지기능 감퇴 및 시지각 능력의 감퇴와 관련이 있다고 하였다 
(Albert, 1981). 이러한 요인들을 살펴보았을 때, 본 연구 결과 에 나타난 두 집단의 수행력의 차이는 이름대기 과제 수행과 관련된 인지기능, 즉 뇌의 기능 퇴화와 같은 신경병리적 특징과 관련이 있는 것으로 생각된다. 본 연구에서 인지 능력과 이름대 기 점수 간 상관관계는 높은 양의 상관관계가 있었으며 $(\mathrm{r}=$ $0.749, p<0.01)$, 의사소통 삶의 질과 이름대기 점수 간에도 높 은 양의 상관관계가 있었다 $(\mathrm{r}=0.620, p<0.01)$. 이처럼 의사 소통에 영향을 주는 요소인 이름대기 능력 역시 인지기능의 문 제로 인하여 어려움을 나타내며, 이름대기 수행력을 통하여 정 상 노년층과 인지기능의 문제가 있는 노년층을 구분할 수 있는 영역이기도 하다. 뿐만 아니라 이름대기의 어려움은 의사소통에 문제를 야기하여 의사소통과 관련된 삶의 질 저하를 가져오는 것을 알 수 있다.

\section{인지기능과 의사소통 삶의 질}

본 연구에서 $\mathrm{MCI}$ 노년층은 정상 노년층 집단보다 $\mathrm{QCL}$ 의 점 수가 낮은 것을 알 수 있었다. 즉, 인지기능에 문제가 있을수록 $\mathrm{QCL}$ 의 점수가 낮게 평가되었다. 정상 노년층 집단과 $\mathrm{MCI}$ 노년 층 집단의 $\mathrm{QCL}$ 의 하부 요인 점수를 비교하였을 때, $\mathrm{MCI}$ 노년 층 집단이 의사소통의 자신감 및 자율성, 역할 및 자아, 일상생 활 참여, 타인과의 상호작용과 관련된 문항들이 정상 노년층 집단보다 통계적으로 유의하게 낮게 나타났다. 이는 전반적인 인지 능력 및 고차원적인 인지 능력과 노인의 의사소통 관련 삶의 질은 매우 상관성이 높다는 선행연구(Lee, 2019)와 일치 하였다. 또한 정상 노년층 집단과 $\mathrm{MCI}$ 노년층 집단의 의사소통 삶의 질 척도 문항별 획득 점수를 비교하였을 때, 총 17 개의 문 항에서 모두 $\mathrm{MCI}$ 노년층 집단이 정상 노년층 집단보다 유의하 게 점수가 낮게 나타났다. 이는 의사소통 삶의 질 척도가 노화 로 인한 인지기능의 문제가 있는 대상과 그렇지 않은 대상에게 있어 의사소통 삶의 질 평가에 적절한 도구임을 의미하며, $\mathrm{MCI}$ 노년층 집단이 정상 노년층 집단에 비해 의사소통의 어려움으 로 인하여 삶의 질이 낮음을 다시 한 번 확인할 수 있었다. 본 연구에서 의사소통 삶의 질의 평가에서 통계적으로 유의하게 낮은 점수를 얻는 $\mathrm{MCI}$ 노년층 집단의 연구 결과를 보았을 때, 인지기능의 저하는 전반적인 삶의 질과 함께 의사소통의 삶의 질에도 영향을 준다는 것을 시사한다.

인지 능력과 인지 능력의 하위 능력의 의사소통 삶의 질과의 상관관계를 살펴보기 위하여 $\mathrm{K}-\mathrm{MoCA}$ 의 총점과 $\mathrm{K}-\mathrm{MoCA}$ 의 하위 능력의 집행 능력, 시공간 구성 능력, 기억력, 주의집중력, 언어 능력, 지남력의 각각의 점수와 의사소통 삶의 질 척도 총 점을 이용하여 상관관계를 살펴보았을 때, $\mathrm{K}-\mathrm{MoCA}$ 의 총점과 $\mathrm{QCL}$ 총점은 통계적으로 높은 수준의 유의한 상관관계가 있는 것으로 나타났다 $(\mathrm{r}=0.728, p<0.01)$. 의사소통 삶의 질에 유
의한 영향을 미치는 $\mathrm{K}-\mathrm{MoCA}$ 의 하위 능력과 $\mathrm{QCL}$ 의 상관관계 를 보았을 때 $\mathrm{K}-\mathrm{MoCA}$ 의 6가지 하위 능력 중 시공간 구성 능 력과 가장 상관성이 높았으며, 주의집중력, 기억력, 집행 능력, 언어 능력, 지남력 순으로 상관성을 보였다. 인지 능력과 의사소 통 삶의 질 간의 상관성은 다양한 측면에서 논의되어 왔다. 뇌 의 구조적, 기능적인 변화를 초래한다는 신경학적 차원을 살펴 보았을 때 노화의 정상적인 과정에서 뇌의 무게와 용적은 10 $15 \%$ 까지 감소하게 되며, 그로 인하여 전전두엽(prefrontal cortex) 및 전두엽, 두정엽 내 회백질(gray matter)의 용량이 줄어 들게 되면서 급격한 뇌 위축(brain atrophy)이 발생하고 뇌의 위축으로 인해 시공간 처리와 작업기억, 집행기능의 과제에서 노인의 수행력이 낮게 나타나게 된다(Raz et al., 2005; Resnick et al., 2003). 최근 Lee(2019)의 연구에 의하면 노인의 의사소 통 관련 삶의 질과 전반적 인지 능력 및 고차원적 인지 능력은 매우 높은 상관성을 가진다고 보고하였다. 특히 문제 해결력, 추론력, 조직화 능력, 집행기능과 같은 고차원적인 인지 능력은 복합적인 인지 언어적 처리에 광범위하게 관여한다고 하였으며, 따라서 의사소통에 근간하는 다양한 수준의 인지-언어 능력의 파악은 의사소통과 관련된 삶의 질을 높일 수 있는 가장 효율 적인 방법이라고 하였다. 이와 같이 6 가지의 $\mathrm{K}-\mathrm{MoCA}$ 의 하위 능력은 정상적인 노화 또는 병리적인 노화로 인하여 뇌의 기능 변화, 용량의 변화로 인하여 기능이 저하되며 이러한 기능의 저 하는 의사소통과 의사소통의 삶의 질에 영향을 주게 된다. 본 연구 결과 시공간 구성 능력은 $\mathrm{K}-\mathrm{MoCA}$ 의 하위 능력 중 의사 소통 삶의 질과 가장 높은 상관성을 보였는데, Johnson et al.(2009)의 연구에서는 시공간 과제가 노인의 지속적인 인지 저하의 예측에 유용하다고 강조하였다. 따라서 시공간 구성 능 력 검사는 다른 인지 능력의 검사보다 인지장애를 민감하게 보 여 줄 수 있다는 것을 의미하며, 시공간 능력에 문제가 있을 경 우 인지 능력뿐만 아니라 의사소통 삶의 질에도 부정적인 영향 을 준다는 것을 시사하였다. 따라서 정상 노년층뿐 아니라 경도 인지장애를 가지는 노년층의 의사소통의 삶의 질을 높이기 위 해서는 언어적인 측면의 이름대기뿐만 아니라 인지적인 측면 중에서 노년기의 의사소통 삶의 질에 가장 큰 영향을 미친 시 공간 구성 능력에 관한 중재를 적용하고, 이외에 다른 여러 인 지 능력(주의집중력, 기억력, 집행기능 등)에 대한 중재도 함께 고려되어야 할 것이다.

본 연구는 정상 노년층을 포함하여 치매 전 단계인 경도인지 장애를 가진 노년층의 의사소통 삶의 질을 예측할 수 있는 여 러가지 인지 능력과 이름대기 능력에 한하여 연관성을 살펴보 았다. 하지만 본 연구에서는 선별 인지기능검사인 몬트리올검 사를 이용하여 다양한 문항을 포함한 인지기능을 면밀히 검토 하지 못하였다. 추후 연구에서는 좀 더 많은 문항 수를 포함하 
는 종합 인지기능검사를 사용하여 인지기능을 살펴볼 필요가 있다. 또한 85세 이상의 초고령 노인까지 포함하여 의사소통의 삶의 질에 영향을 미칠 수 있는 다양한 인지기능을 찾아내어 노인기 의사소통 중재에 사용할 수 있을 것이다. 본 연구 참여 자의 대부분이 홀로 사시는 1 인 가구 어르신이 대부분이었는 데, 최근 홀로 사는 노인이나 장기 입원 환자들을 대상으로 하 는 '말벗 도우미' 봉사가 있다. 초고령화 시대를 눈앞에 두고 노 년기 의사소통 중재에 좀 더 언어재활사와 같은 전문가가 참여 할 수 있도록 제도적 뒷받침이 필요하며, 치매 예방 및 인지기 능 향상과 더불어 의사소통에 대한 자신감 및 자율성, 역할 및 자아, 일상생활 참여, 타인과의 상호작용을 높이기 위한 중재 전략으로 노년층의 전반적인 의사소통 삶의 질 향상에 기여할 수 있을 것이다.

중심 단어 : 인지기능·이름대기 능력·의사소통 삶의 질·노인.

\section{Ethical Statement}

In this study, the experiment was carried out based on the consent of the subject after being deliberated by the Daegu Catholic University Bioethics Committee (IRB: CUIRB-2019-0022).

\section{Acknowledgments} N/A

\section{Declaration of Conflicting Interests}

There are no conflict of interests.

\section{Funding}

N/A

\section{Author Contributions}

All authors contributed equally to this work. J.P. designed and performed experiments, analyzed data, and wrote the paper; K.L. and C.C. designed experiments and commented statistical analysis; S.C. designed experiments and provided statistical analysis and critical revision.

\section{ORCID iDs}

Ji Young Park Seong Hee Choi

https://orcid.org/0000-0002-0725-5896 https://orcid.org/0000-0003-2365-6187

\section{REFERENCES}

Albert, M. S. (1981). Geriatric neuropsychology. Journal of Consulting and Clinical Psychology, 49(6), 835-850.

Balthazar, M. L. F., Cendes, F., \& Damasceno, B. P. (2008). Semantic error patterns on the Boston naming test in normal aging, amnestic mild cognitive impairment, and mild Alzheimer's disease: Is there semantic disruption. Neuropsychology, 22(6), 703-709.

Caccappolo-Van Vliet, E., Manly, J., Tang, M. X., Marder, K., Bell, K., \& Stem, Y. (2003). The neuropsychological profiles of mild Alzheimer's disease and questionable dementia as compared to age-related cognitive decline. Journal of the International Neuropsychological Society, 9(5), 720-732.

Calero, M. D., López Pérez-Díaz, A. G., Navarro González, E., \& CaleroGarcía, M. J. (2013). Cognitive plasticity, cognitive functioning and quality of life (QoL) in a sample of young-old and old-old adults in southern Spain. Aging Clinical and Experimental Research, 25(1), 35-42.

Choi, H. Y., Kim, Y. W., Rha, D. W., \& Kim, H. H. (2011). The quality of communication life scale-Korean version. Communiaction Sciences and Disorders, 16(3), 388-396.

Duong, A., Whitehead, V., Hanratty, K., \& Chertkow, H. (2006). The nature of lexico-semantic processing deficits in mild cognitive impairment. Neuropsychologia, 44(10), 1928-1935.

Glisky, E. L. (2007). Changes in cognitive function in human aging. In Riddle, D. R. Brain Aging: Models, Methods, and Mechanisms (pp. 1-9). New York, NY: CRC Press.

Gorske, T. T., Daley, D. C., Yenerall, E., \& Morrow, L. A. (2006). Neuropsychological function and employment status in a welfare-to-work sample. Applied Neuropsychology, 13(3), 141-150.

Han, E. S. (2014). Association of cognitive impairment with frailty in community-dwelling older adults (Unpublished doctoral dissertation). Graduate School of Ajou University, Suwon.

Hwang, Y. K. \& Kim, H. H. (2014). Utility of the Boston naming test in differentiating between mild cognitive impairment and normal elderly: A meta-analysis. Communication Sciences and Disorders, 19(4), 501-512.

Jefferson, A. L., Wong, S., Gracer, T. S., Ozonoff, A., Green, R. C., \& Stern, R. A. (2007). Geriatric performance on an abbreviated version of the Boston naming test. Applied Neuropsychology, 14(3), 215-223.

Johns, E. K., Phillips, N. A., Belleville, S., Goupil, D., Babins, L., Kelner, N., et al. (2012). The profile of executive functioning in amnestic mild cognitive impairment: Disproportionate deficits in inhibitory control. Journal of the International Neuropsychological Society, 18(3), 541-555.

Johnson, D. K., Storandt, M., Morris, J. C., \& Galvin, J. E. (2009). Longitudinal study of the transition from healthy aging to Alzheimer disease. Archives of Neurology, 66(10), 1254-1259.

Juncos-Rabadán O., Pereiro, A. X., \& Rodríguez, M. S. (2005). Narrative speech in aging: Quantity, information content, and cohesion. Brain and Language, 95(3), 423-434.

Kang, S. K., Kim, D. Y., Seok, D. L., Cho, H. J., \& Choi, K. H. (2000). A study of the aged diseases. Journal of Special Education, 16(1), 1-32.

Kang, Y. W., Kim, H. H., \& Na, D. L. (1999). A short form of the KoreanBoston naming test (K-BNT) for using in dementia patients. Korean Journal of Clinical Psychology, 18(2), 125-138.

Kang, Y. W., Park, J. S., Yu, K. H., \& Lee, B. C. (2009). A reliability validity, and normative study of the Korean-Montreal cognitive assessment (K$\mathrm{MoCA}$ ) as an instrument for screening of vascular cognitive impairment (VCI). Korean Journal of Clinical Psychology, 28(2), 549-562.

Kaplan, E., Goodglass, H., \& Weintraub, S. (1983). Boston Naming Test. Philadelphia, PA: Lea \& Febiger.

Kim, H. H. \& Kim, S. R. (2013). Development of short form of the Korean version-the Boston naming test (K-BNT-15) based on item response theory. The Journal of the Korea Contents Association, 13(12), 321-327.

Kim, H. H. \& Na, D. L. (1997). Korean Version-Boston Naming Test (K$B N T)$. Seoul: Hakjisa.

Kim, J. W. \& Kim, H. H. (2009). Communicative ability in normal aging: A review. Communication Sciences and Disorders, 14(4), 495-513.

Kim, J. W., Hwang, J. H., Kim, S. R., \& Kim, H. H. (2013). Differences in attention and naming ability with age in the elderly. Journal of Speech and Hearing Disorders, 22(3), 25-44.

Lee, M. S. (2019). Factors affecting quality of communication life in older adults: Focused on the relationship with quality of life, cognition, and psychoemotional aspects. Audiology and Speech Research, 15(3), 232240.

Lee, S. B. (2013a). The effects of proprioceptive exercise and strengthening exercise on balance ability in elderly. Journal of Korea Entertainment Industry Association, 7(4), 173-177.

Lee, S. H. (2013b). Characteristics of memory beliefs and memory strategies in patients with mild cognitive impairment. The Graduate School of Kyungpook National University, Daegu.

Maseda, A., Lodeiro-Fernández, L., Lorenzo-López, L., Núñez-Naveira, L., Balo, A., \& Millán-Calenti, J. C. (2014). Verbal fluency, naming and 
verbal comprehension: Three aspects of language as predictors of cognitive impairment. Aging and Mental Health, 18(8), 1037-1045.

Mioshi, E., Dawson, K., Mitchell, J., Arnold, R., \& Hodges, J. R. (2006). The Addenbrooke's cognitive examination revised (ACE-R): A brief cognitive test battery for dementia screening. International Journal of Geriatric Psychiatry, 21(11), 1078-1085.

Morra, J. H., Tu, Z., Apostolova, L. G., Green, A. E., Avedissian, C., Madsen, S. K., et al. (2009). Automated 3D mapping of hippocampal atrophy and its clinical correlates in 400 subjects with Alzheimer's disease, mild cognitive impairment, and elderly controls. Human Brain Mapping, 30(9), 2766-2788.

Park, E. \& Chey, J. (2000). Elderly normative study of the short form Korean-Boston naming test. Korean Journal of Cognitive Science, 11(2), 5968.

Paul, D. R., Frattali, C. M., Holland, A. L., Thompson, C. K., Caperton, C. J., \& Slater, S. C. (2004). Quality of Communication Life Scale. Rockville, MD: ASHA.

Petersen, R. C., Caracciolo, B., Brayne, C., Gauthier, S., Jelic, V., \& Fratiglioni, L. (2014). Mild cognitive impairment: A concept in evolution. Journal of Internal Medicine, 275(3), 214-228.

Petersen, R. C. \& Morris, J. C. (2003). Mild cognitive impairment: Aging to Alzheimer's disease. In Petersen, R. C. Clinicalfeatures (pp. 15-40). New York, NY: Oxford University Press, Inc.
Raz, N., Lindenberger, U., Rodrigue, K. M., Kennedy, K. M., Head, D., Williamson, A., et al. (2005). Regional brain changes in aging healthy adults: General trends, individual differences and modifiers. Cerebral Cortex, 15(11), 1676-1689.

Resnick, S. M., Pham, D. L., Kraut, M. A., Zonderman, A. B., \& Davatzikos, C. (2003). Longitudinal magnetic resonance imaging studies of older adults: A shrinking brain. Journal of Neuroscience, 23(8), 3295-3301.

Sung, J. A. (2007). A study on the cognitive function and quality of life in the elderly people living at home (Unpublished doctoral dissertation). Ewha Womans University, Seoul.

Swainson, R., Hodges, J. R., Galton, C. J., Semple, J., Micheal, A., Dunn, B. D., et al. (2001). Early detection and differential diagnosis of Alzheimer's disease and depression with neuropsychological tasks. Dementia and Geriatric Cognitive Disorders, 12(4), 265-280.

Verhaeghen, P. (2003). Aging and vocabulary scores: A meta-analysis. Psychology and Aging, 18(2), 332-339.

Woo, H. R. \& Kim, J. W. (2015). Different cognitive profiles between mild cognitive impairment and normal elderly depending on the type of attention and naming tasks. Journal of Rehabilitation Research, 19(2), 297-314.

Woo, H. R. (2014). The naming ability and attention in normal elderly and mild cognitive impairment (Unpublished master's thesis). Daegu University, Gyeongsan. 